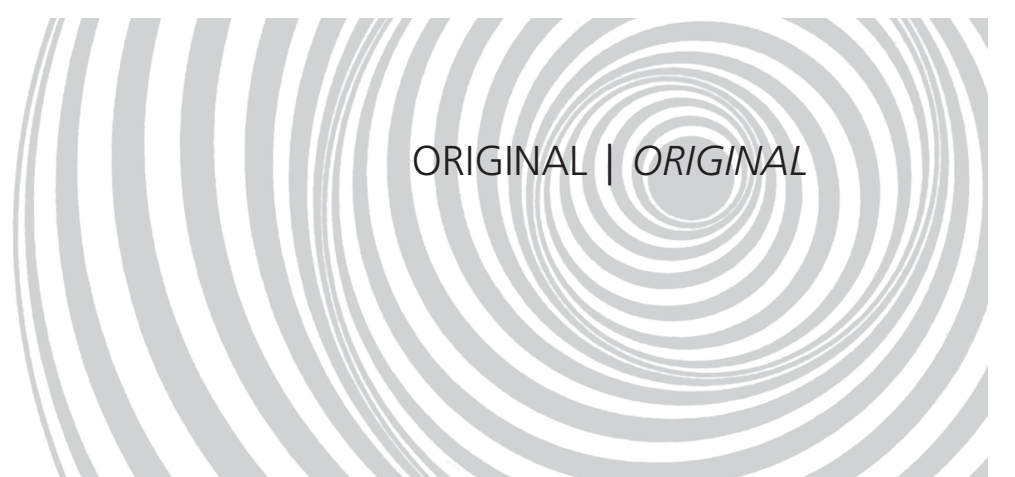

\title{
Contaminação bacteriana e fúngica de canudos de refrigerantes e seus recipientes em lanchonetes de município do interior de São Paulo
}

\author{
Fungal and bacterial contamination of drinking \\ straws and their containers in snack bars in \\ a municipality of São Paulo state, Brazil
}

Francisco Rafael Martins SOTO'

Eliana de OLIVEIRA ${ }^{1}$

Edson Hideki SAKAGUTI'

Yara Solange Kubo FONSECA²

Heloisa Gimenes Gil DIAS²

Maria Cláudia Lopez ${ }^{2}$

Sérgio Santos de AZEVEDO ${ }^{3}$

RE S U M O

\section{Objetivo}

Avaliar o nível de contaminação bacteriana e fúngica de canudos de refrigerantes e seus recipientes em 30 lanchonetes do Município de Ibiúna (SP), correlacionando com as condições de higiene, processos e métodos de desinfecção destes estabelecimentos.

\section{Métodos}

Foram colhidas três amostras por estabelecimento nas embalagens fechadas, em recipientes e swab em toda a superfície de contato. Foi aplicado um questionário a fim de avaliar: a empresa fornecedora dos canudos, higienização, freqüência e desinfecção, e foram efetuadas inspeções sanitárias nos estabelecimentos. Para as análises microbiológicas foi utilizada a técnica de lavagem superficial e semeadura em meios, para contagem de bactérias mesófilas. As amostras turvas foram semeadas em meios de cultura para: Staphylococcus aureus, Bacillus cereus, Pseudomonas aeruginosa, Enterococcus, coliformes totais e/ou termotolerantes.

1 Secretaria Municipal da Saúde, Centro de Vigilância Sanitária e Controle de Zoonoses Tereza Rodrigues de Camargo. R. Ribeirão Pires, s/n., Bairro dos Paes, 18150-000, Ibiúna, SP, Brasil. Correspondência para/Correspondence to: F.R.M. SOTO.

E-mail: <chicosoto34@gmail.com>

2 Instituto Adolfo Lutz, Laboratório de Microbiologia Alimentar. Sorocaba, SP, Brasil.

${ }^{3}$ Universidade Federal de Campina Grande, Unidade Acadêmica de Medicina Veterinária, Campus de Patos. Patos, PB, Brasil. 


\section{Resultados}

Dentre os microorganismos isolados nas amostras dos canudos nos recipientes foi detectado Bacillus cereus em 36,6\%, Enterococo spp. em 3,3\%. O Bacillus cereus foi isolado em 46,6\% nos swabs dos recipientes, e em $13,3 \%$, Enterococos. Na análise de associação do nível de contaminação microbiana de canudos de refrigerantes e seus recipientes com as condições de higiene, os processos de higienização e a desinfecção dos estabelecimentos, não foi identifica significância estatística $(p>0,05)$.

\section{Conclusão}

O Bacillus cereus foi o microorganismo que prevaleceu nas embalagens íntegras dos canudos, nos seus recipientes e no swab das superfícies. Não foi comprovada a associação de fatores de risco de contaminação bacteriana e fúngica.

Termos de indexação: Bactérias. Contaminação. Fungos. Recipientes de alimentos.

\section{A B S T R A C T}

\section{Objective}

The objective of this study was to evaluate the fungal and bacterial contamination level of drinking straws and their containers of thirty snack bars at the municipality of Ibiuna (SP, Brazil) and to correlate these data with conditions of hygiene and the processes and methods of disinfection of these establishments.

\section{Methods}

Three samples of closed packages, containers and contact surface swabs were collected in each establishment. A questionnaire was administered to identify the straws supplier, hygiene methods, frequency and disinfection. Sanitary inspections were also performed in these establishments. Microbiological analyses were done using the superficial washing technique and seeding plates to count mesophilic bacteria, mold and yeasts. Turbid samples were seeded in culture media for: Staphylococcus aureus, Bacillus cereus, Pseudomonas aeruginosa, Enterococcus, total and/or thermotolerant coliforms.

\section{Results}

Microorganisms isolated from samples of drinking straws were Bacillus cereus $36.6 \%$, Enterococcus spp and Molds/yeasts 3.3\%. Swabs of containers revealed $46.6 \%$ of Bacillus cereus and $13.3 \%$ of Enterococcus. Association analyses of the microbial contamination level of drinking straws and their containers with conditions of hygiene, hygiene processes and disinfection of the establishments did not show statistical significance (p>0.05).

\section{Conclusion}

Bacillus cereus was the most prevalent microorganism in closed packages, containers and surface swabs. No statistical association of risk factors for bacterial or fungal contamination was found.

Indexing terms: Bacterial. Contamination. Funga. Food packaging.

\section{N T R O D U ÇÃ O}

As doenças de origem alimentar, principalmente causadas por bactérias ou suas toxinas, têm sido reconhecidas como um problema de saúde pública de grande abrangência no mundo, causando morbidade e mortalidade na população, perdas econômicas e afetando a confiança do consumidor nos estabelecimentos comerciais de alimentos envolvidos no episódio ${ }^{1-3}$.

A contaminação dos alimentos ou seus recipientes se inicia na produção da matéria-prima e se estende às etapas de transporte, recepção e armazenamento. Durante a manipulação pode haver contaminação por condições precárias de higiene de manipuladores, equipamentos, utensílios, ambiente e condições inadequadas de armazenamento dos produtos prontos para o consumo ${ }^{4,5}$.

Dentre os microorganismos de origem bacteriana de relevância em saúde pública, que podem contaminar alimentos ou recipientes nos quais estes estão armazenados, e que podem estar presentes em grande quantidade no ambien- 
te de manipulação de alimentos, os mais importantes são: Staphylococcus aureus, Escherichia coli, Clostridium spp. e Bacillus cereus ${ }^{6,7}$.

O Staphylococcus aureus pode produzir doença tanto por sua capacidade de multiplicação e disseminação ampla nos tecidos, como pela produção de muitas substâncias extra-celulares, como a enterotoxina, que é uma causa importante de intoxicação alimentar, sendo produzida, principalmente, quando certas cepas crescem em alimentos contendo carboidratos e proteínas ${ }^{8-10}$.

Os grupos de coliformes totais e fecais colonizam o trato intestinal de animais de sangue quente, incluindo os humanos, e têm sido empregados como indicadores de qualidade higiênica por muitos anos em estabelecimentos de alimentos $^{11,12}$. Apesar das controvérsias com relação aos microorganismos mais representativos da qualidade sanitária de um produto alimentício ou de seu recipiente, os coliformes, em geral, a Escherichia coli têm merecido maior consideração. A despeito de os coliformes serem ou não inadequados indicadores da segurança microbiológica da água, dos alimentos e dos recipientes, os membros desse grupo de microorganismos continuam sendo usados internacionalmente para esse fim $^{13,14}$.

Dentre as principais bactérias esporuladas, as mais resistentes ao calor, e de importância na microbiologia alimentar, pertencem aos gêneros Bacillus e Clostridium ${ }^{15,16}$.

Nas espécies do gênero Bacillus, uma das mais importantes na indústria de alimentos é o Bacillus cereus, tendo em vista sua capacidade de produzir toxinas, responsáveis por toxinfecções alimentares, enzimas extracelulares, que determinam o potencial de deterioração, e esporos, que podem resistir às adversidades do meio ambiente $^{17}$. A simples presença do patógeno em locais e em condições que possibilitem sua eventual transferência para alimentos prontos é, reconhecidamente, um fator importante para desencadear episódios de intoxicações, muitos dos quais sequer vêm a ser diagnosticados ${ }^{17}$. Tal consideração ressalta a importância de identificar pontos do ambiente ou diversos recipientes utilizados pelos consumidores em lanchonetes, como canudos de refrigerantes, que possam representar fontes de contaminação.

Este trabalho teve por objetivo avaliar o nível de contaminação bacteriana e fúngica de canudos de refrigerantes e seus recipientes, em lanchonetes do Município de Ibiúna (SP), correlacionando às condições de higiene, aos processos de higienização e à desinfecção dos estabelecimentos. Com base neste diagnóstico, será possível orientar medidas efetivas de controle destes patógenos e, em particular, possíveis ações corretivas em processos de higienização.

\section{M É T O D O S}

A pesquisa foi efetuada em 30 lanchonetes escolhidas aleatoriamente na área central do Município de Ibiúna, no período de julho a novembro de 2007 , representando $67 \%$ do total destes estabelecimentos. Foram colhidas 3 amostras por lanchonete, e 90 no total, sendo a primeira de canudos de refrigerantes acondicionados nas embalagens fechadas, a segunda de armazenados em recipientes disponíveis no balcão (local que foi definido como de atendimento aos clientes) dos estabelecimentos, sem proteção individual dos canudos, e a terceira a partir da utilização de swab agar na forma de gel para transporte bacteriológico, em toda a superfície de contato do recipiente com os canudos. Nas embalagens fechadas foram colhidas amostras de 10 diferentes empresas produtoras de canudos plásticos. Para a colheita das amostras foram utilizados sacos plásticos e luvas estéreis, para evitar a contaminação cruzada, e as mesmas foram enviadas no mesmo dia para o Laboratório de Microbiologia Alimentar do Instituto Adolfo Lutz.

As pessoas que auxiliaram nas colheitas das amostras e no diagnóstico microbiológico não tiveram acesso aos dados referentes aos canudos armazenados em embalagens fechadas e nos recipientes, sendo esta informação exclusiva do coordenador do estudo. 
Foi aplicado um questionário em todas as lanchonetes que participaram da pesquisa, a fim de avaliar a empresa fornecedora dos canudos, o processo, se a mesma efetuava ou não higienização dos recipientes, a freqüência de higienização e desinfecção dos recipientes dos canudos, sendo classificada como diária, semanal, quinzenal, mensal e a utilização ou não de detergentes e/ou desinfetantes. Foram efetuadas inspeções sanitárias nos estabelecimentos, que foram classificados em: insatisfatórios, satisfatórios com restrição e satisfatórios em relação às condições higiênico-sanitárias dos mesmos. Para ser definida esta classificação, foram considerados seis itens principais, na apresentação ou não de conformidades: instalações e equipamentos, utensílios, higiene pessoal dos manipuladores de alimentos, qualidade dos produtos expostos à venda, manipulação dos alimentos e a documentação sanitária.

Para as análises microbiológicas dos canudos colhidos nos recipientes ou na embalagem fechada, foi utilizada a técnica de lavagem superficial ${ }^{18}$. Toda a amostra foi picada e transferida assepticamente para um frasco estéril contendo $180 \mathrm{~mL}$ de Água Peptonada (AP) 0,1\% e, após agitação por 30 minutos em agitador de Kline, foi diretamente semeada em meios para Contagem de Bactérias Mesófilas (CPP), Bolores e Leveduras (OGY). A seguir, o frasco com o restante do inoculo, foi incubado à temperatura de $35^{\circ} \mathrm{C}$ (com variação de $1^{\circ} \mathrm{C}$ ) por 24 a 48 horas, para observação da ocorrência ou não de turvação do diluente.

Os swabs colhidos dos recipientes nos quais os canudos estavam acondicionados foram transferidos para um caldo de enriquecimento seletivo Brain Hearth Infusion (BHI) e incubados a $35^{\circ} \mathrm{C}$ (com variação de $1^{\circ} \mathrm{C}$ ), por 24 a 48 horas, para a observação da turvação ou não do meio.

As amostras turvas (AP 0,1\% e BHI) foram semeadas em meios de cultura para a pesquisa de: Staphylococcus aureus, Bacillus cereus, Pseudomonas aeruginosa, Enterococcus, coliformes totais e/ou termotolerantes. Após a semeadura e a incubação em tempo e temperatura específicos para cada microorganismo foi realizada a confirmação/identificação bioquímica.
Todas as informações colhidas da pesquisa foram armazenadas e compiladas em planilhas do Programa Excel.

Para a comparação da proporção de amostras com contaminação (embalagens fechadas, armazenados em recipientes e swab agar na forma de gel) foi utilizado o teste binomial. A análise de associação do nível de contaminação bacteriana de canudos de refrigerantes e seus recipientes às condições de higiene, aos processos de higienização e à desinfecção dos estabelecimentos foi feita pelo teste de qui-quadrado ${ }^{19}$. As análises foram realizadas com o programa SPSS for Windows versão 13.0 e o nível de significância adotado foi de $5 \%$.

\section{RES ULTADOS}

Das 30 lanchonetes que participaram da pesquisa, todas efetuavam, pelo menos, algum tipo de higienização nos recipientes dos canudos, sendo que a freqüência diária deste processo foi diagnosticada em duas $(6,6 \%)$, semanal em 24 $(80,0 \%)$, quinzenal em duas $(6,6 \%)$ e mensal em duas $(6,6 \%)$. Do total dos estabelecimentos, 7 $(23,3 \%)$ utilizavam água corrente na higienização, 14 (46,6\%) associação de água e detergente e 9 (30,0\%) água, detergente e, ao final, desinfecção com álcool.

$\mathrm{Na}$ inspeção sanitária efetuada nas lanchonetes, uma $(3,3 \%)$ foi classificada como insatisfatória, $13(43,3 \%)$ como satisfatórias com restrição e 16 (53,3\%) satisfatórias.

Na Tabela 1 está apresentada a freqüência de microorganismos isolados de origem bacteriana e fúngica na embalagem fechada de canudos plásticos, armazenados no recipiente e após utilização de swab nas lanchonetes.

Em relação à presença de contaminação microbiana nas embalagens fechadas das empresas produtoras de canudos, $40,0 \%$ das marcas foram positivas para o Bacillus cereus, sendo que em $81,2 \%$ das amostras, estas foram originárias de duas empresas com freqüência de isolamento do microorganismo de $50,0 \%$ e $31,2 \%$. 
Tabela 1. Distribuição percentual de microorganismos isolados de origem bacteriana e fúngica em embalagem fechada de canudos plásticos, armazenados em recipiente e após utilização de swab, em lanchonetes da área central do Município de lbiúna (SP), 2007.

\begin{tabular}{|c|c|c|c|c|c|c|}
\hline \multirow{2}{*}{ Microorganismo } & \multicolumn{2}{|c|}{ Embalagem fechada } & \multicolumn{2}{|c|}{ Canudo no recipiente } & \multicolumn{2}{|c|}{ Swab do recipiente } \\
\hline & $\mathrm{n}$ & $\%$ & $n$ & $\%$ & $n$ & $\%$ \\
\hline Bacillus cereus & $16 / 30$ & 53,33 & $11 / 30$ & 36,66 & $14 / 30$ & 46,66 \\
\hline Enterococo spp. & $00 / 30$ & 0 & $01 / 30$ & 3,33 & $04 / 30$ & 13,33 \\
\hline Bolores/Levedura & $01 / 30$ & 3,33 & $01 / 30$ & 3,33 & $00 / 30$ & 0 \\
\hline
\end{tabular}

Tabela 2. Distribuição percentual de fatores de risco de contaminação microbiana e fúngica em embalagem fechada de canudos plásticos, armazenados em recipiente e após utilização de swab, em lanchonetes da área central do Município de Ibiúna (SP), 2007.

\begin{tabular}{|c|c|c|c|c|c|c|c|c|c|c|c|c|}
\hline \multirow{3}{*}{ Fatores de risco de contaminação } & \multicolumn{12}{|c|}{ Presença a contaminação } \\
\hline & \multicolumn{4}{|c|}{ Embalagens fechadas } & \multicolumn{4}{|c|}{ Recipientes } & \multicolumn{4}{|c|}{ Swab } \\
\hline & Sim & $\%$ & Não & $\%$ & Sim & $\%$ & Não & $\%$ & Sim & $\%$ & Não & $\%$ \\
\hline \multicolumn{13}{|l|}{ Higienização dos recipientes } \\
\hline Sim & 11 & 36,7 & 19 & 63,3 & 17 & 56,7 & 13 & 43,3 & 16 & 53,3 & 14 & 46,7 \\
\hline \multicolumn{13}{|l|}{ Freqüência de higienização } \\
\hline Diária & 0 & 0,0 & 2 & 100,0 & 1 & 50,0 & 1 & 50,0 & 1 & 50,0 & 1 & 50,0 \\
\hline Semanal & 9 & 37,5 & 15 & 62,5 & 13 & 54,2 & 11 & 45,8 & 12 & 50,0 & 12 & 50,0 \\
\hline Quinzenal & 1 & 50,0 & 1 & 50,0 & 1 & 50,0 & 1 & 50,0 & 1 & 50,0 & 1 & 50,0 \\
\hline Mensal & 1 & 50,0 & 1 & 50,0 & 2 & 100,0 & 0 & 0,0 & 2 & 100,0 & 0 & 0,0 \\
\hline \multicolumn{13}{|l|}{ Produtos utilizados } \\
\hline Água & 4 & 57,1 & 3 & 42,9 & 3 & 42,9 & 4 & 57,1 & 3 & 42,9 & 4 & 57,1 \\
\hline Água e detergente & 5 & 35,7 & 9 & 64,3 & 10 & 71,4 & 4 & 28,6 & 7 & 50,0 & 7 & 50,0 \\
\hline Água, detergente e desinfetante & 2 & 22,2 & 7 & 77,8 & 4 & 44,4 & 5 & 55,6 & 6 & 66,7 & 3 & 33,3 \\
\hline \multicolumn{13}{|l|}{ Condição higiênico-sanitária } \\
\hline Insatisfatória & 1 & 100,0 & 0 & 0,0 & 1 & 100,0 & 0 & 0,0 & 1 & 100,0 & 0 & 0,0 \\
\hline Satisfatória com restrição & 0 & 46,2 & 7 & 53,8 & 8 & 61,5 & 5 & 38,5 & 8 & 61,5 & 5 & 38,5 \\
\hline Satisfatória & 4 & 25,0 & 12 & 75,5 & 8 & 50,0 & 8 & 50,0 & 7 & 43,8 & 9 & 56,2 \\
\hline
\end{tabular}

Na Tabela 2 é exposta a distribuição percentual de fatores de risco de contaminação microbiana e fúngica na embalagem fechada de canudos plásticos, armazenados no recipiente e após utilização de swab da superfície de contato. $\mathrm{Na}$ análise de associação do nível de contaminação bacteriana de canudos de refrigerantes e seus recipientes às condições de higiene, aos processos de higienização e à desinfecção dos estabelecimentos, não houve significância estatística $(p>0,05)$.

\section{DISCUSSÃO}

A maioria das lanchonetes inspecionadas $(53,3 \%)$ apresentou-se como satisfatória com restrição, em relação às condições higiênico-sanitárias, e os resultados obtidos em relação aos processos de higienização e desinfecção dos recipientes dos canudos e sua exposição, indicaram falhas nesta etapa, pois apenas $6,6 \%$ dos estabelecimentos efetuavam a sua higienização diariamente, e somente 30,0\% de forma correta, utilizando desinfecção ao final do procedimento. Este diagnóstico indicou que, provavelmente, erros neste processo poderiam estar ocorrendo em outros pontos nas lanchonetes, principalmente nas áreas de manipulação de alimentos, favorecendo assim a contaminação microbiana e fúngica nestes locais, sendo o recipiente de canudos, objeto de pesquisa neste trabalho, apenas um parâmetro 
destas falhas. Entretanto, não foi detectada significância estatística destes fatores de risco com a contaminação microbiana e fúngica dos canudos nas embalagens íntegras, nos recipientes e no swab da superfície (Tabela 2). Mendes et al. ${ }^{20}$ detectaram a presença de Bacillus cereus em $27,0 \%$ do total de amostras colhidas nas superfícies de bancadas de Unidades de Alimentação e Nutrição.

Dentre os microorganismos isolados nas amostras dos canudos nos recipientes prevaleceu o Bacillus cereus com a sua ocorrência em 36,6\% das amostras. Em menor porcentagem (3,3\%) foram diagnosticados Enterococo spp. e Bolores/ Leveduras. O Bacillus cereus foi isolado também em $46,6 \%$ nos swabs dos recipientes, e em 13,3\% foi diagnosticado Enterococo. A capacidade de esporulação do Bacillus cereus em superfícies de manipulação de alimentos ou em seus recipientes que oferecem baixa disponibilidade de nutrientes ou ausência, tem sido relatada por vários autores $^{21-24}$. A presença de Enterococo tanto nos swabs, este em maior incidência, como nos canudos expostos nos recipientes, em menor porcentagem, é um sinal de que ocorreram falhas na manipulação e na higienização, principalmente nos recipientes. Em 53,3\% das amostras nas embalagens íntegras os resultados foram positivos para o Bacillus cereus. Este resultado é um indicativo de que a contaminação também ocorreu e/ou se iniciou no processo de fabricação dos canudos em $40,0 \%$ das empresas cujas amostras foram analisadas, e a maior ocorrência do Bacillus cereus $(81,2 \%)$ ficou concentrada em duas empresas, havendo necessidade de correção e revisão nos Procedimentos Operacionais de Produção (POP), bem como a notificação destes estabelecimentos fabris pela vigilância sanitária. Processos eficientes de higienização e desinfecção são fundamentais para evitar a presença do Bacillus cereus e sua posterior esporulação. No caso específico de canudos de refrigerantes, a orientação de utilização de embalagem individual e protegida contra microorganismos patogênicos, prática adotada para alguns alimentos consumidos em lanchonetes ainda de forma tímida, e em pequena porcena- gem para canudos, deveria ser encorajada e ampliada pela vigilância sanitária para vários alimentos e recipientes, reduzindo assim os riscos de contaminação ${ }^{25-27}$. No Brasil, ainda não há legislação de âmbito nacional que trata deste tema especificamente, o que dificulta ações corretivas pelos órgãos reguladores. Alguns municípios brasileiros, como na cidade do Rio de Janeiro, têm aprovado leis municipais a respeito da obrigatoriedade do uso de embalagens protetoras contra a contaminação de origem biológica nos canudos de refrigerantes ${ }^{28}$, o que contribui para a redução dos riscos sanitários.

Frente à patogenicidade do Bacillus cereus e à sua capacidade de multiplicação em ampla faixa de temperatura, a simples detecção desta bactéria em canudos de refrigerantes e em seus recipientes é importante, sob o ponto de vista da saúde pública, em relação ao risco de intoxicações alimentares. Trabalhos têm apontado este microorganismo como responsável por casos de intoxicações alimentares no mundo. Hernando et al. ${ }^{29}$ relataram surto de intoxicação por Bacillus cereus em um presídio na Espanha, onde mais de 100 presidiários apresentaram severo quadro de diarréia e dores abdominais. No Brasil, Estado de São Paulo, no Município de Ibiúna, Soto et al. ${ }^{30}$ descreveram intoxicação alimentar em 120 operários de uma empreiteira cujo microorganismo responsável foi também o Bacillus cereus, representando prejuízo para a saúde pública e para a empresa pelos dias de trabalho perdidos pelos funcionários.

\section{O N CLUS Ã O}

De acordo com os resultados conclui-se que a Bacillus cereus foi o microorganismo que prevaleceu nas embalagens integras dos canudos, nos seus recipientes e no swab das superfícies, destacando, assim, a importância desta bactéria como possível desencadeadora de quadros de intoxicação alimentar. Porém não foi comprovada a associação de fatores de risco de contaminação bacteriana e fúngica e a presença destes microor- 
ganismos na embalagem fechada de canudos plásticos, armazenados no recipiente e após utilização de swab em lanchonetes da área central do Município de Ibiúna (SP).

São necessárias intervenções no controle higiênico-sanitário, desde a etapa fabril até a exposição para o consumidor dos canudos de refrigerantes e seus recipientes. A aprovação de leis regulamentando todas as fases de produção dos canudos de refrigerantes poderá contribuir com a redução dos riscos sanitários inerentes ao produto.

A prática de utilização de embalagens individuais e protegidas de canudos deve ser implantada nas lanchonetes, para que a possibilidade de contaminação de origem bacteriana ou fúngica seja reduzida nestes estabelecimentos.

Como formas de continuidade deste estudo, novas avaliações microbiológicas e de fatores de risco, após a implantação das intervenções propostas, poderão contribuir para o avanço do controle higiênico-sanitário de recipientes e de produtos comumente utilizados em lanchonetes.

\section{COLABORADORES}

F.R.M. SOTO, autor principal, foi o idealizador e coordenador do projeto e fez a redação do artigo. E. OLIVEIRA e E.H. SAKAGUTI colheram as amostras no campo, aplicaram o questionário e efetuaram o diagnóstico higiênico-sanitário das lanchonetes. Y.S.K. FONSECA, M.C. LOPEZ e H.G.G. DIAS contribuíram com a redação do artigo no item metodologia, e realizaram o diagnóstico laboratorial das amostras colhidas. S.S. AZEVEDO contribuiu com a redação do artigo no item metodologia e com os resultados e efetuou a análise estatística

\section{REFERÊ N CIAS}

1. Ristow AM, Silva MJA, Ferreira LMF, Souza KF, Cortez NMS, Miranda ZB. Avaliação higiênico-sanitária das unidades de alimentação e nutrição localizadas nos Campi de uma Universidade do Rio de Janeiro. Rev Hig Aliment. 2007; 21(150):356.

2. Mennuci TA, Souza TAM, Chaaban HMA. Prevenção de doenças transmitidas por alimentos em cozinhas residenciais: uma abordagem educativa da vigilância sanitária de Diadema. Rev Hig Aliment. 2007; 21(150):372.

3. Mesquita MO, Daniel AP, Saccol ALF, Milani LIG, Fries LM. Qualidade microbiológica no processamento do frango assado em unidade de alimentação e nutrição. Ciênc Tecnol Aliment. 2006; 26(1):198-203. doi: 10.1590/S0101-20612006 000100031.

4. Zandonadi RP, Botelho RB, Assunção SK, Oliveira E. Atitudes de risco do consumidor em restaurantes de auto-serviço. Rev Nutr. 2007; 20(1):19-26. doi: 10.1590/S1415-52732007000100002.

5. Rodrigues LB, Soares J, Camargo CB, Trenhago G, Oliveira AP, Orsato J, et al. Avaliação microbiológica de superfícies de contato em um matadouro de aves. Rev Hig Aliment. 2007; 21(150):195.

6. Germano PML, Germano MIS. Higiene e vigilância sanitária de alimentos. São Paulo: Livraria Varela; 2001.

7. Cereser ND, Martineli TM, Felipe LM, Rossi OD, Berwanger ML, Barcelos AS. Qualidade microbiológica de lingüiças frescais de produção industrial. Rev Hig Aliment. 2007; 21(150):208.

8. Frazier WC, Westhoff DC. Food microbiology. 4th ed. New York: McGraw-Hill; 1988.

9. Freitas MFL, Leão AMDS, Stamford, TLM, Mota RA. Ocorrência de Staphylococcus aureus em caraças de frangos. Bol CEPPA. 2004; 22(2):100-5.

10. Adams M, Moss MO. Food microbiology. 2nd ed. Cambridge: Royal Society of Chemistry; 2002.

11. Calci KR, Burkhardt W, Watkins WD. Occurrence of male-specific bacteriophage in fecal and domestic animal wastes, human feces and humanassociated wastewaters. Appl Envir Microbiol. 1998; 64(12):5027-29. doi: 10.1590/50103-8478 2001000600024.

12. Guimarães AM. Freqüência de enteroparasitas em amostras de alface (Lactuca sativa) comercializadas em Lavras, Minas Gerais. Rev Soc Bras Med Trop. 2003; 36(5):10-20. doi: 10.1590/S0037-868220 03000500014 .

13. Loguercio AP, Aleixo J, Guimarães A Microbiologia de queijo tipo Minas Frescal produzido artesanalmente. Ciênc Rur. 2001; 31(6):1063-7. doi: 10. 1590/S0103-84782001000600024.

14. Karch $H$, Bielaszewska M, Sorbitol M. Fermeting Shiga toxin producing Escherichia coli O 157: $\mathrm{H}$ - strains: epidemiology, phenotypic and molecular characteristics and microbiological diagnosis. J Clin Microbiol. 2001; 39(6): 2043-2049. doi: 10.1128/JCM.39.6.2043-2049.2001.

15. Rangasamy PN, lyer M, Roginski H. Isolation and characterisation of Bacillus cereus in milk and dairy 
products manufactured in Victoria. Aust J Dairy Technol. 1993; 48:93-5. doi:10.1016S0168-1605 (96) 01204-4.

16. Cosentino S, Mulargia AF. Incidence and biochemical characteristics of Bacillus flora in Sardinian dairy products. Int J Food Microbiol. 1997; 38(2-3):235-8. doi:10. 1016/S0168-1605 (97)00107-4

17. Rodrigues KL, Gomes JP, Conceição RC, Brod CS, Carvalhal JB, Aleixo JAG. Condições higiênico-sanitárias no comércio ambulante de alimentos em Pelotas-RS. Cienc Tecnol Aliment. 2003; 23(3): 447-52. doi: 10.1590/S0101-206120030003000 26.

18. Silva N, Junqueira VCA, Silveira NFA. Manual de métodos de análise microbiológica de alimentos. 2a. ed. São Paulo: Livraria Varela; 2001.

19. Siegel S, Castellan NJ. Estatística não-paramétrica para as ciências do comportamento. 2a. ed. Porto Alegre: Artmed; 2006.

20. Mendes RA, Azeredo RMC, Coelho AIM, Oliveira SS, Coelho MSL. Contaminação ambiental por Bacillus cereus em unidade de alimentação e nutrição. Rev Nutr. 2004; 17(2):255-61. doi: 10.1590/S 1415-52732004000200012.

21. Hornstra LM, Leeuw PL, Moezelaar R, Wolbert EJ, Uries YP, Vos WM, et al. Germination of Bacillus cereus spores adhered to stainless steel. Int J Food Microbiol. 2007; 116(3):367-71.

22. Faille C, Tauveron G, Le Gentil LC, Slomiamy C. Occurrence of Bacillus cereus spores with a damaged exosporium: consequences on the spore adhesion on surfaces of food processing lines. J Food Prot. 2007; 70(10):2346-53. doi: PROD2008 $11 \mathrm{c} 89 \mathrm{~d} 81$.

23. Vidal-Martins AMC, Rossi JR OD, Rezende-Lago, NC. Microrganismos heterotróficos mesófilos e bactérias do grupo do Bacillus cereus em leite integral submetido a ultra alta temperatura. Arq Bras Med Vet Zootec. 2005; 57(3):396-400. doi: 10.1590/S0102-09352005000300019.

24. King NJ, Whyte R, Hudson JA. Presence and significance of Bacillus cereus in dehydrated potato products. J Food Prot. 2007; 70 (2):514-20.

25. Hoobs BC, Roberts D. Toxinfecções e controle higiênico-sanitário de alimentos. São Paulo: Varela; 1999.

26. Cassane AB, Fernandez AT, Silva MF. Pesquisa de $E$. coli resistente a antimicrobianos em amostras de salada mista, queijo minas frescal e frios fracionados comercializados em Duque de Caxias. Rev Hig Aliment. 2007; 21 (150):208.

27. Nascimento AR, Fialho JEM, Martins AGAL, Bayma $A B$, Gomes SV, et al. Incidência de Escherichia coli e Salmonella em alface (Lactuca sativa). Rev Hig Aliment. 2005; 19(128):121-124.

28. Câmara Municipal do Rio de Janeiro, Lei n 3.655, de $1^{\circ}$ de outubro de 2003. Obriga restaurantes, bares, lanchonetes, barracas de praia, ambulantes e similares autorizados pela Prefeitura a usarem e fornecerem canudos de plástico individual e hermeticamente embalados. Diário Oficial Rio. 2003 out 2.

29. Hernando V, Arranz NL, Catalan S, Gomez P, Hidalgo C, Barrasa $A$, et al. Investigation of a foodborne intoxication in a high-density penitentiary center. Gac Sanit. 2007; 21(6):452-7.

30. Soto FRM, Dias GMA, Fonseca YSK. Toxinfecção Alimentar por Bacillus cereus- Relato de caso. Rev Hig Aliment. 2005; 19(130):33-7.

Recebido em: 17/12/2007

Versão final reapresentada em: 3/7/2008 Aprovado em: 17/9/2008 